\title{
ELEMENTOS E FUNDAMENTOS PARA A CONCEPÇÃO DE UM SISTEMA DE MOBILIDADE URBANA ORIENTADO Å INCLUSÃO SOCIAL
}

\author{
ELEMENTS AND FUNDAMENTALS TO THE CONCEPTION OF AN URBAN MOBILITY \\ SYSTEM ORIENTED TO SOCIAL INCLUSION
}

\author{
Ana Stéfany da SILVA Gonzaga \\ Arquiteta e Urbanista - Universidade Federal do Rio de Janeiro \\ ana.gonzaga@pet.coppe.ufrj.br \\ Licínio da SILVA PORTUGAL \\ Engenheiro Civil - Universidade Federal do Rio de Janeiro \\ licinio@pet.coppe.ufri.br

\section{Érika Cristine KNEIB} \\ Arquiteta e Urbanista -Universidade Federal de Goiás \\ erikacristine@gmail.com
}

\section{Resumo}

Há na literatura um crescente interesse dos pesquisadores em estudar a exclusão social e suas relações com os transportes, que envolvem conceitos complexos aos quais outros elementos intervenientes estão relacionados. Entretanto, ainda há uma ênfase aos transportes e a um tratamento fragmentado, o que aponta para a necessidade de se ampliar esse enfoque, se estendendo a todo o Sistema de Mobilidade Urbana (SMU). A partir de tal lacuna observada na literatura consultada e confirmada em uma pesquisa bibliométrica, apresenta-se uma proposta com os elementos e fundamentos que podem contribuir para a concepção de um SMU orientado à inclusão social. Tal concepção pretende contribuir para uma melhor compreensão acerca das relações entre o SMU e a inclusão social, proporcionando uma visão integrada e estratégica a ser considerada na elaboração dos Planos de Mobilidade Urbana Sustentável, algo fundamental, especialmente em contextos urbanos desiguais e com deficiências no planejamento, como verificado em países latinoamericanos.

Palavras-chave: Inclusão social; Acessibilidade; Transporte; Uso do Solo; Sistema de Mobilidade Urbana.

\footnotetext{
Abstract

The literature reflects the growing interest of researchers in studying social exclusion and its relations with transportation. It involves complex concepts related to other intervening elements. However, the questions about transportation generally receive fragmented treatment, indicating the need to take a broader view to encompass the entire urban mobility system (UMS). Because of the gaps in the literature noted based on a bibliometric
} 
review, this paper presents a proposal with elements and fundamentals that can contribute to the conception of a UMS oriented to social inclusion. This concept aims to contribute to a better understanding of the interplay of UMSs and social inclusion, providing an integrated and strategic vision to be considered when formulating sustainable urban mobility plans. It is imperative, especially in urban settings with high inequality and poor planning, as seen in Latin American countries.

Keywords: Social inclusion; Accessibility; Transport; Land Use; Urban Mobility System.

\section{INTRODUÇÃO}

A exclusão social está relacionada ao conceito de privação, ou seja, afeta a qualidade de vida e reflete um estado de desvantagem em relação à comunidade local, à sociedade ou nação em geral na qual um indivíduo ou grupo se insere (PRINGLE; WALSH, 1999). Também há uma relação da exclusão social com o conceito de pobreza, que está mais diretamente relacionado à renda dos indivíduos e é referente à falta de recursos materiais. No entanto, apesar de ser uma condição fortemente associada à exclusão social, é possível que pessoas sejam excluídas socialmente sem, necessariamente, serem consideradas pobres. Para Atkinson (1999), enquanto pobreza e privação são entendidas como resultados, a exclusão social se caracteriza como um processo e envolve interações entre vários fatores contribuintes ao longo do tempo. A exclusão social também está ligada à falta de participação em atividades, o que envolve o exercício de cidadania (BURCHARDT et al., 2002).

A exclusão social é um conceito amplo e complexo, centrada em processos que resultam no acesso desigual às oportunidades oferecidas à sociedade (WANG et al., 2020). Dentre suas consequências estão barreiras que dificultam ou até mesmo impedem que os indivíduos participem de atividades. Dessa forma, a exclusão pode prejudicar o exercício da cidadania, pois envolve uma multiplicidade de fatores impeditivos ao acesso e à realização de atividades (CHURCH et al., 2000; KENYON et al., 2002; GRAY; FARRINGTON, 2006). Tais fatores podem acentuar os processos de privação, principalmente dos segmentos populacionais mais vulneráveis e em desvantagem. Isso justifica a preocupação com as restrições de acesso às oportunidades, que contribuem para afetar a mobilidade desejada (SEU, 2003; FALAVIGNA et al., 2017).

Esse contexto tem motivado, desde o final dos anos 1990 (LUCAS, 2004), várias pesquisas a buscarem entender o papel dos transportes relacionado à exclusão social (CHURCH et al., 2000; KENYON, 2003; CURRIE, 2011; NEUTENS et al., 2014; KAMRUZZAMAN et al., 2016; GIUFFRIDA et al., 2017). Nesse sentido, observa-se o 
desenvolvimento de estudos que começaram a tornar mais explícitas as relações entre pobreza, desvantagem de transporte, acesso a serviços essenciais e exclusão econômica e social (LUCAS, 2012). Entretanto, os fatores excludentes não se limitam isoladamente às questões relacionadas aos transportes, pois também envolvem fatores como a exclusão geográfica, características do ambiente local (SCHWANEN et al., 2015), dentre outros. Segundo Pucci et al. (2019), as pesquisas sobre exclusão social relacionada aos transportes têm confirmado a importância de envolver outros elementos, como a mobilidade - como condição para participação em atividades - e a acessibilidade - como requisito fundamental para a inclusão social.

Apesar dessa preocupação, o protagonismo dado aos transportes pode ser a razão pela qual, frequentemente, resultados inconclusivos são produzidos nos estudos que buscam compreender e explicar a exclusão social (SILVA, 2013). Além disso, poucas abordagens trabalham esse tema de forma abrangente e integrada, como exige qualquer estudo que pretenda entender a exclusão social e sua inserção no Sistema de Mobilidade Urbana (SMU), que abrange os deslocamentos das pessoas em uma cidade destinados ao desenvolvimento de suas atividades e relações sociais e econômicas (PRITCHARD et al., 2014; PITTMAN; DAY, 2015; WANG et al., 2020).

Esta lacuna tem apontado para a necessidade de se ampliar o enfoque (LUCAS, 2004; CASS et al., 2005; CURRIE, 2011; SILVA, 2013; MATTIOLI; COLLEONI, 2016; KAMRUZZMAN et al., 2016). Essa percepção se tornou evidente, pois, ainda que o pensamento científico procure dividir um problema em partes menores para melhor compreendê-lo, problemas complexos (que envolvem muitas variáveis ou questões sociais, por exemplo) constituem uma gama de elementos em interação, o que requer abordagens baseadas na noção de sistema (BERTALANFFY, 2010). Este trabalho estuda a exclusão social enfatizando aquela relacionada à falta de realização de atividades, decorrente das restrições de acesso físico aos locais em que tais atividades se encontram e respectivas consequências na mobilidade das pessoas. Ele se justifica na medida em que o planejamento inadequado do SMU pode contribuir para a exclusão social ao provocar limitações de acessibilidade que afetam de forma desigual certos grupos populacionais (NEUTENS et al., 2014).

Em contextos urbanos desiguais, como no caso do Brasil, condições desfavoráveis de acesso às atividades para pessoas de baixa renda são resultantes de um processo histórico marcado pelo desenvolvimento urbano modelado por especulações no mercado imobiliário e por políticas públicas de planejamento ausentes do princípio da equidade 
(SILVA, 2013). O espraiamento urbano aumenta os tempos de viagem da população residente em áreas periféricas, dificulta o acesso às diversas atividades disponíveis no território, prejudicando a mobilidade e reforçando a exclusão social (CARNEIRO et al., 2019). As cidades brasileiras, em sua maioria, sofrem consequências da segregação espacial e das disparidades nos níveis de acesso às atividades, além de graves deficiências infraestruturais (FALAVIGNA et al., 2017). Com isso, as redes de transporte público não satisfazem às necessidades dos grupos sociais em desvantagem, além de serem, em muitos casos, consideradas inacessíveis financeiramente para uma significativa parcela da população de baixa renda (CARRUTHERS et al., 2005). Além disso, os Planos de Mobilidade, pautados em abordagens tradicionais, não têm conseguido reverter esta situação (PORTUGAL; MELLO, 2017) e costumam ser criticados por apresentarem propostas muitas vezes não conectadas à realidade (GARCIA et al., 2018).

A partir das lacunas encontradas na literatura, bem como da importância da garantia de acesso às atividades para a promoção da inclusão social, este trabalho tem como objetivo identificar os elementos e alguns fundamentos para a concepção de um Sistema de Mobilidade Urbana (SMU) orientado à inclusão social. Com foco nesse objetivo, este trabalho pretende: (i) estabelecer quais elementos devem ser considerados nos estudos sobre exclusão social relacionada às restrições de acesso às localidades e que afetam a mobilidade, o que contribui para provável não realização de atividades e (ii) sugerir a forma através da qual tais elementos deveriam ser organizados e abordados.

A metodologia usada neste trabalho consiste na aplicação de uma revisão de literatura e de uma pesquisa bibliométrica e, a partir dos resultados obtidos, recomendar alguns fundamentos para a concepção de um SMU orientado à inclusão social. A revisão de literatura foi utilizada para identificar os principais elementos e fundamentos a serem trabalhados. Lacunas da revisão de literatura também foram observadas na revisão bibliométrica, aplicada para identificar como a literatura aborda tais elementos e fundamentos. Além disso, a abordagem sistêmica foi sugerida e utilizada como ferramenta para organizar e abordar os elementos do SMU. De acordo com esta proposta, o artigo foi estruturado nas seguintes seções. Na Seção 2 são identificados, com base na revisão da literatura, os principais elementos e respectivas características que, além dos transportes, costumam ser usados nos estudos sobre exclusão social. $\mathrm{Na}$ Seção 3, o propósito é verificar, de acordo com uma pesquisa bibliométrica e com os elementos que se destacaram na revisão de literatura, se o enfoque usado é isolado, 
como no caso dos transportes, ou se é mais abrangente, envolvendo desejavelmente todos os elementos indicados. Na seção 4, a partir dos resultados alcançados nas seções anteriores, pretende-se apresentar alguns fundamentos que contribuam para a concepção de um SMU orientado à inclusão social. Na Seção 5 são apresentadas as conclusões do trabalho.

\section{EXCLUSÃO SOCIAL NO ÂMBITO DO SISTEMA DE MOBILIDADE URBANA: UM PANORAMA DA LITERATURA}

Conforme destacado inicialmente, a exclusão social é um conceito que pode ser entendido como um processo que envolve interações entre vários fatores contribuintes ao longo do tempo (ATKINSON, 1999) e que resulta em privação para determinados grupos ou indivíduos (PRINGLE; WALSH, 1999). Além disso, é multiescalar, afeta indivíduos, mas também bairros e comunidades, incluindo aspectos geográficos (SCHWANEN et al., 2015). A complexidade e amplitude da exclusão estão relacionadas à pobreza e desemprego (na dimensão econômica); crimes, baixos níveis de educação, falta de direitos sociais e de acesso adequado aos serviços de saúde (na dimensão social); baixa participação em grupos e organizações (na dimensão política); questões ligadas ao gênero, religião, idade, cor da pele, raça, nacionalidade (na dimensão pessoal); características do bairro onde se vive, isolamento geográfico, dentre outros (KENYON et al., 2002). Essa multiplicidade de fatores, que inclui também os aspectos imateriais, torna ainda mais complexa a análise da exclusão (CHURCH et al., 2000; KENYON et al., 2002).

Se a exclusão social está ligada a não participação em atividades, a inclusão considera a participação em todos os tipos de atividades (GRAY; FARRINGTON, 2006), o que pressupõe que elas podem ser acessadas. Nesse sentido, o conceito de exclusão social está associado às dificuldades para acessar as atividades, o que requer valorizar os transportes, mas também outros fatores que interferem em tais condições de acesso. No entanto, observa-se na literatura um predomínio atribuído aos transportes nos estudos sobre exclusão social (MATTIOLI; COLLEONI, 2016), tratado de forma isolada em detrimento de uma visão mais abrangente e integrada (SILVA, 2013), o que tem sido criticado em trabalhos como o de Lucas (2004), Cass et al. (2005), Currie (2011), Mattioli e Colleoni (2016) e Kamruzzman et al. (2016).

No caso do Brasil, condições desfavoráveis de acesso às atividades para pessoas de baixa renda são resultantes de um processo histórico marcado por um desenvolvimento urbano modelado por especulações no mercado imobiliário e por 
políticas públicas de planejamento urbano excludentes (SILVA, 2013). O espraiamento urbano aumenta os tempos de viagem da população residente de áreas periféricas, dificulta $\mathrm{o}$ acesso às diversas oportunidades disponíveis no território, prejudicando a mobilidade e reforçando a exclusão social (CARNEIRO et al., 2019). As cidades brasileiras, em sua maioria, sofrem consequências da segregação espacial e das disparidades nos níveis de acesso às oportunidades, além de graves deficiências infraestruturais (FALAVIGNA et al., 2017). Com isso, as redes de transporte público não satisfazem às necessidades dos grupos sociais em desvantagem, além de serem, em muitos casos, consideradas inacessíveis financeiramente para uma significativa parcela da população de baixa renda (CARRUTHERS et al., 2005).

Os processos de exclusão social podem, ainda, ser potencializados através da desigualdade. Esta, por sua vez, é um conceito que compreende o estabelecimento de condições de acesso desproporcionais aos recursos, oriundo das divisões sociais. A desigualdade social resulta em algum grau de injustiça, ou seja, estabelece situações em que características sociais sistematicamente colocam alguns grupos em desvantagem com relação às oportunidades existentes (SANTOS, 2006; BARATA, 2009). No âmbito da necessidade de deslocamento físico para acesso às atividades, o conceito de desvantagem de transportes inclui características individuais como capacidade física e social, que podem limitar o acesso pessoal, como acontece com idosos, jovens desempregados, pessoas de baixa renda ou com barreiras culturais e linguísticas (GIUFFRIDA et al., 2017). Com relação à influência das desigualdades relativas ao transporte sobre o bem-estar das pessoas, Pereira et al. (2020) enfatizam três tipos: desigualdades de recursos relacionados ao transporte, comportamento diário de viagem observado e níveis de acessibilidade ao transporte. Apesar de interferirem na realização ou não da viagem e na forma como ela ocorre, olhar para as condições oferecidas pelos recursos não exprime de forma mais ampla a capacidade real dos indivíduos de utilizar tais recursos para se mover pela cidade e alcançar as atividades desejadas. Para autores como Mullen (2012) e Lyons (2006), as decisões de transporte são principalmente uma questão de escolha individual e responsabilidade pessoal. A programação de viagens envolve escolhas que vão além dos modos de transporte, o que inclui observar também se o indivíduo realiza ou não deslocamentos para alcançar atividades, bem como os horários e destinos. Tais padrões de viagens são influenciados pelos transportes, uso do solo e acessibilidade e expressam a mobilidade (PEDRO et al., 2017). 
Características do uso do solo como a densidade, diversidade, desenho urbano, destinos acessíveis e disponibilidade de serviços de transportes, conhecidas como 5 Ds (EWING; CERVERO, 2001) estão entre os elementos capazes de promover autonomia, dinamismo, equidade e qualidade de vida para toda uma vizinhança. Tais condições locais pressupõem uma distribuição equitativa destas atividades ao longo de todo o território urbano (PORTUGAL, 2017). Dentre os fatores referentes ao uso do solo que podem afetar a exclusão social está o isolamento físico de indivíduos, que dificulta o acesso destes aos sistemas de transportes e às localidades (CHURCH et al., 2000). uso do solo exerce significativa influência no acesso dos indivíduos às localidades para realização de atividades, pois estabelece uma relação de interdependência com os transportes (HERCE, 2009) e com as características dos indivíduos (MILLER, 2006). A separação espacial entre as principais atividades da vida que exigem a presença ou telepresença em locais fixos no espaço e no tempo, bem como a falta de transportes e tecnologias de informação e comunicação são fatores que configuram as condições de acessibilidade e respectivas impedâncias para a realização (ou não) de atividades (MILLER, 2006; GUTIÉRREZ, 2012).

Nesse sentido, têm-se observado, nos últimos anos, uma tendência de crescimento no interesse científico com relação à questão da exclusão social e como ela está relacionada aos níveis de acessibilidade de diferentes grupos sociais (LUCAS et al., 2001; KENYON, 2003; CURRIE et al., 2007; KAMRUZZAMAN et al., 2016; GIUFFRIDA et al., 2017). Para Neutens et al. (2014), esse interesse dos pesquisadores e planejadores decorre da preocupação quanto ao potencial do planejamento espacial e temporal inadequado em promover a exclusão social. Um avanço percebido na literatura é que a acessibilidade tem sido entendida como um fator facilitador e um indicador das condições fornecidas em uma localidade (CHENG et al., 2007), ou seja, através do qual as oportunidades que as pessoas necessitam podem ser acessadas e, assim, seja evitada a exclusão (NUTLEY, 2003; PUCCI, 2019). A acessibilidade, portanto, exerce influência sobre a exclusão social, pois a falta de acesso acentua as disparidades já existentes no contexto urbano ao reduzir ainda mais as possibilidades de acesso às localidades, principalmente para grupos sociais mais vulneráveis (KNEIB et al., 2017). A acessibilidade é condição necessária, mas não suficiente, para a expansão da liberdade de escolha das pessoas e promoção da igualdade de oportunidades como emprego, saúde, serviços de educação, etc. (PEREIRA et al., 2020). A perspectiva centrada nas pessoas é de 
interesse primordial, visto que o desenvolvimento do transporte sustentável depende de uma mudança no comportamento da mobilidade (SCHWEDES; HOOR, 2019).

Mesmo considerando o papel da acessibilidade de representar a quantidade e tipos de atividades potencialmente alcançáveis, cabe destacar que a decisão de se deslocar e a forma com que se dá tal deslocamento (que expressa a mobilidade) é função das características, capacidades e necessidades dos indivíduos, o que abrange a renda, gênero, idade, sexo, dentre outras (KWAN; WEBER, 2003; VAN WEE; GEURS, 2011; SHERGOLD; PARKHURST, 2012). Para o indivíduo, as escolhas de viagem envolvem compensações de atributos conflitantes, dentre os quais o custo, tempo de viagem, conforto, segurança e outros (GAO et al., 2021). Dimensões sociais são relevantes para as questões de acesso e exclusão social, pois restrições de espaço-tempo e padrões de atividade variam conforme os principais fatores sociais, como disponibilidade de veículos, status socioeconômico, estilo de vida, tamanho e organização da família e outros (MILLER, 2006). A partir da relação do uso do solo com os transportes e da interferência que ele exerce sobre as condições de acesso e, consequentemente, nos padrões de viagens (mobilidade) (SILVA, 2013), Ewing e Cervero (2001) destacam que a frequência e duração de viagens são funções das características socioeconômicas dos viajantes e do ambiente construído. As distâncias, os tempos de viagens e a escolha do modo dependem de ambas as características, embora provavelmente mais da condição socioeconômica. Para os autores, os comprimentos das viagens são geralmente mais curtos em locais mais acessíveis, com densidades mais altas ou que apresentam usos mistos.

Além disso, as viagens de rotina também são essenciais para um padrão de vida normal (NUTLEY, 2003), ou seja, requer atenção também para a mobilidade, que resulta da interação entre condições de acesso (pela acessibilidade, que advém da articulação entre transportes e uso do solo) e condições dos indivíduos. A mobilidade é afetada, mas também tem o potencial de afetar outros fatores da exclusão social, fazendo com que pessoas que possuem uma mobilidade inadequada sofram com uma negação de acesso às necessidades básicas como emprego, saúde ou educação (KENYON, 2003). Kenyon et al. (2002) propõem que a exclusão social relacionada à mobilidade ocorre em função da reduzida acessibilidade às oportunidades, serviços e redes sociais, devido, no todo ou em parte, à mobilidade insuficiente em uma sociedade e ambiente construído em torno do pressuposto da alta mobilidade. 
Condições de acesso, representadas pela acessibilidade e sua relação com os transportes e com o uso do solo, somadas às características dos indivíduos, envolvem fatores que podem estabelecer condições limitantes à mobilidade do indivíduo. Para Church et al. (2000), a capacidade de um indivíduo acessar atividades que facilitam a participação está relacionada a fatores que podem restringir a sua mobilidade e, portanto, afetar a exclusão social. A não realização de viagens necessárias constitui a imobilidade que, por sua vez, resulta da falta de capacidade do indivíduo quanto à superação das impedâncias relacionadas às condições de acesso (FALAVIGNA et al., 2017).

O comportamento de viagem individual e coletivo está diretamente relacionado à tomada de decisão dos indivíduos, o que dá origem aos padrões de mobilidade (LYONS, 2006). Na literatura, diversos trabalhos têm destacado que a mobilidade deve ser considerada uma capacidade básica devido ao seu papel central em permitir que as pessoas satisfaçam suas necessidades fundamentais (VAN WEE; GEURS, 2011; PEREIRA et al., 2020). Pesquisas recentes têm considerado o conceito de exclusão social em suas várias dimensões, dentre as quais as desvantagens temporais, espaciais, sociais, econômicas, políticas, pessoais e de mobilidade entre os diferentes grupos sociais (KENYON et al., 2002; BOCAREJO; OVIEDO, 2012; SAIF et al., 2018). Nos últimos 50 anos, tem ocorrido uma mudança de paradigma através da qual a mobilidade tem sido reinterpretada por meio de uma "perspectiva sociotécnica", que já mostra resultados como a redução do uso de automóveis e o incentivo às viagens sustentáveis (JONES, 2014). A abordagem da mobilidade urbana associada ao conceito de sustentabilidade agrega atributos como a redução da exclusão social, melhorias na qualidade de vida, segurança, eficiência energética e redução de emissões de gases de efeito estufa (PORTUGAL; SILVA, 2017).

A partir desta revisão da literatura - através da qual se verifica a ênfase dada aos transportes e a necessidade de se ampliar este enfoque - busca-se responder ao questionamento referente à quais elementos devem ser considerados nos estudos sobre exclusão social no âmbito das condições de mobilidade e de acesso às localidades para realização de atividades. Com esse propósito, destacaram-se os transportes, uso do solo e acessibilidade - que estabelecem as condições de acesso - (MELLO, 2015; KNEIB; PORTUGAL, 2017), os indivíduos - que, a partir de suas condições sociais, econômicas e psicológicas, decidem sobre a realização ou não de deslocamentos (LYONS, 2006; STANLEY et al., 2011; PORTUGAL, 2017) - e a mobilidade - que envolve os deslocamentos e respectivos padrões de viagens, resultantes das condições 
de acesso e de sua interação com os indivíduos (STANLEY et al., 2011; LIMA; PORTUGAL, 2021). Estes cinco elementos fazem parte do SMU e do escopo de atuação dos pesquisadores, formuladores de políticas, planejadores e gerentes do SMU, aos quais a proposta deste artigo se direciona. Dessa forma, o Sistema de Mobilidade Urbana pode ser definido como um conjunto de elementos que interagem entre si e estabelecem as condições de acesso (através da interação entre Transportes e Uso do Solo, o que resulta na Acessibilidade) que, ao interagirem com as condições dos indivíduos, resultam nas condições de mobilidade da população (EWING; CERVERO, 2001; LYONS, 2006; STANLEY et al., 2011; MELLO, 2015; KNEIB; PORTUGAL, 2017; LIMA; PORTUGAL, 2021). Baseada na revisão de literatura, que apontou os principais elementos do SMU e as relações entre eles, tal definição é uma das contribuições deste artigo. A Figura 1, a seguir, ilustra o SMU e seus elementos.

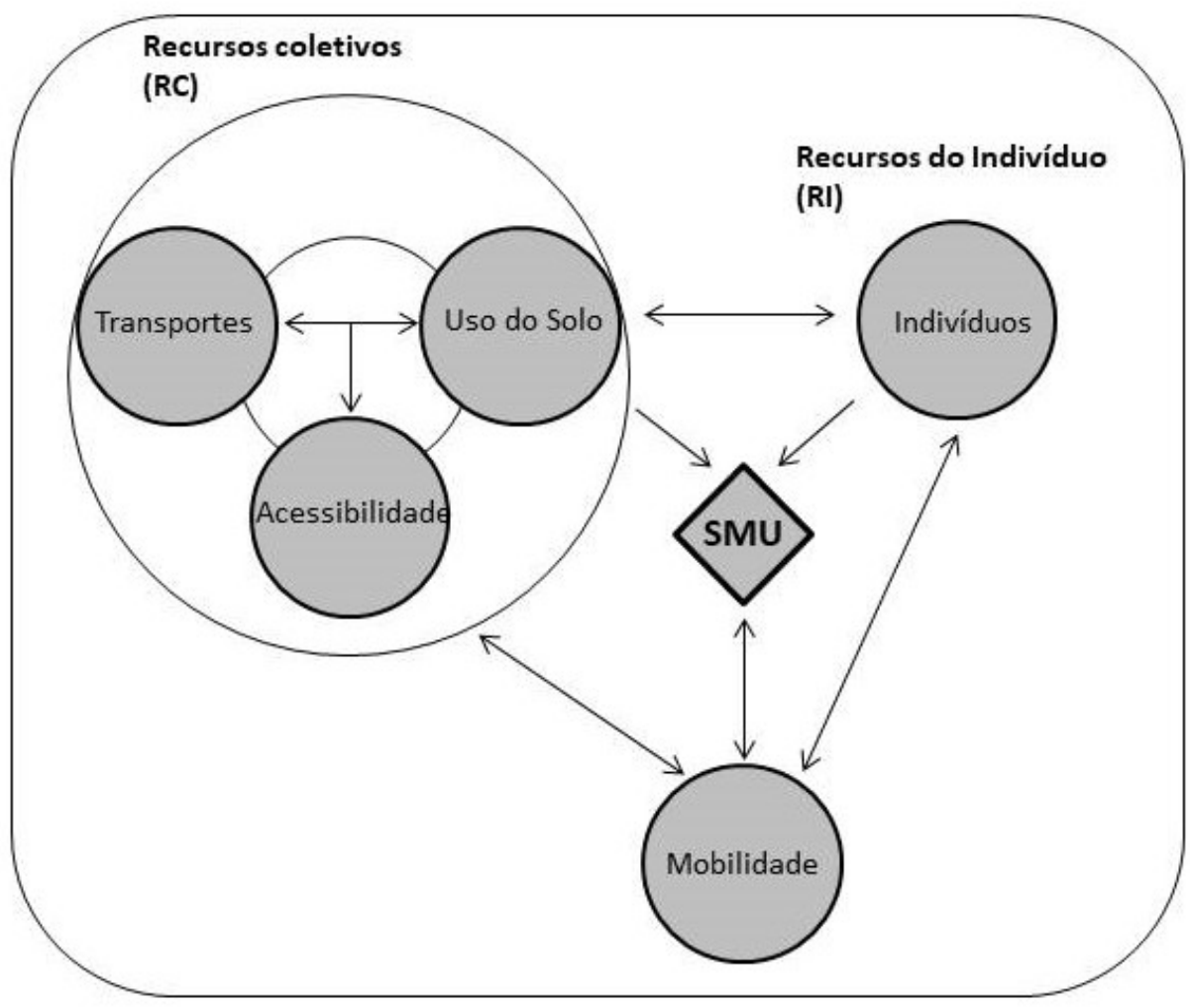

Figura 1 - SMU e seus elementos.

Fonte: própria.

Para ser efetivamente compreendido como um sistema, o SMU requer o atributo da abrangência, pois nenhum de seus elementos é capaz de, isoladamente, superar as restrições de acessibilidade e solucionar os problemas de mobilidade urbana. A natureza de interdependência e de interação, explicitada anteriormente entre tais elementos, que influenciam e são influenciados pela exclusão social, promove um contexto de alta 
complexidade. Tais relações sugerem uma abordagem sistêmica, o que justifica incluir nesse processo de análise todos os 5 elementos que compõem o SMU. Esta abrangência é fundamental nos estudos sobre exclusão social para que o SMU seja orientado à inclusão social quanto às condições de mobilidade e de acesso às atividades. Nesse sentido, utiliza-se, a seguir, a pesquisa bibliométrica como instrumento para verificar como a literatura trata este quesito de abrangência, que envolve os cinco elementos do SMU a partir de uma abordagem sistêmica.

\section{PESQUISA BIBLIOMÉTRICA COM BASE NOS ELEMENTOS DO SMU E NA EXCLUSÃO SOCIAL}

A pesquisa bibliométrica foi realizada neste trabalho com o propósito de observar se os elementos do SMU, identificados na Seção 2, têm sido tratados de forma isolada, como no caso dos transportes, ou abrangente, envolvendo desejavelmente todos os elementos do SMU. A bibliometria é útil quando se pretende observar o desenvolvimento de determinada área de conhecimento através da análise de publicações científicas disponíveis em grandes bases de dados (GUTIÉRREZ-SALCEDO et al., 2018). Nesta pesquisa, as bases de dados Scopus e Web of Science foram utilizadas para encontrar artigos científicos a partir de buscas nas quais foram aplicadas diferentes combinações das palavras-chave organizando-as em grupos de duas, três, quatro e cinco palavras, são elas: "Transport", "Land use", "Accessibility", "Individual/People", "Mobility". Tais palavraschave se referem aos elementos que fazem parte do SMU e o número de palavras considerado nas combinações corresponde ao número de elementos do SMU contemplados pelos artigos. O termo "Social exclusion" fez parte de todas as combinações. Em cada uma das buscas foi realizada, ainda, uma filtragem de maneira a concentrar os resultados nas áreas relacionadas a este trabalho. Para isso, foram excluídos das buscas artigos relacionados, por exemplo, às áreas de "Agricultural and Biological Sciences", "Computer Science", "Medicine", "Biochemistry, Genetics and Molecular Biology", "Mathematics", "Physics and Astronomy", "Immunology and Microbiology", "Veterinary", "Nursing", "Health professions", "Neuroscience”, "Dentistry" dentre outras. Artigos duplicados tiveram um dos exemplares excluídos da contagem. A tabela 01 apresenta os quantitativos de artigos encontrados em cada uma das combinações de palavras, nas duas bases de dados utilizadas. Na coluna "Totais por busca", os valores apresentados representam todos os trabalhos encontrados em cada uma das buscas. Na coluna "Total sem duplicados", os valores representam todos os 
trabalhos encontrados, retirando-se os duplicados, em cada uma das etapas que reúne todas as buscas com uma, duas, três, quatro e cinco palavras-chave vinculados aos 5 elementos do SMU aqui investigados.

Tabela 1 - Quantitativos de trabalhos encontrados na pesquisa bibliométrica a partir de combinações de palavras-chave.

\begin{tabular}{|c|c|c|c|c|c|c|c|}
\hline \multicolumn{8}{|c|}{ Quantitativos de trabalhos encontrados a partir de combinações de palavras-chave } \\
\hline \multicolumn{5}{|c|}{ Combinações com duas palavras + social exclusion } & $\begin{array}{l}\text { Totais por } \\
\text { busca }\end{array}$ & $\begin{array}{l}\text { Total sem } \\
\text { duplicados }\end{array}$ & Percentual \\
\hline Transport & Land use & & & & 78 & \multirow{10}{*}{860} & \multirow{10}{*}{$74,33 \%$} \\
\hline Transport & Accessibility & & & & 320 & & \\
\hline Transport & Individual/People & & & & 322 & & \\
\hline Transport & Mobility & & & & 369 & & \\
\hline Land use & Accessibility & & & & 62 & & \\
\hline Land use & Individual/People & & & & 220 & & \\
\hline Land use & Mobility & & & & 70 & & \\
\hline Accessibility & Individual/People & & & & 262 & & \\
\hline Accessibility & Mobility & & & & 257 & & \\
\hline Individual/People & Mobility & & & & 411 & & \\
\hline \multicolumn{5}{|c|}{ Combinações com três palavras + social exclusion } & $\begin{array}{l}\text { Total por } \\
\text { busca }\end{array}$ & $\begin{array}{c}\text { Total sem } \\
\text { duplicidades }\end{array}$ & Percentual \\
\hline Transport & Accessibility & Mobility & & & 190 & \multirow{6}{*}{208} & \multirow{6}{*}{$17,97 \%$} \\
\hline Transport & Accessibility & Land use & & & 34 & & \\
\hline Transport & Accessibility & Individual/People & & & 173 & & \\
\hline Accessibility & Mobility & Land use & & & 24 & & \\
\hline Accessibility & Mobility & Individual/People & & & 154 & & \\
\hline Mobility & Land use & Individual/People & & & 30 & & \\
\hline \multicolumn{5}{|c|}{ Combinações com quatro palavras + social exclusion } & $\begin{array}{l}\text { Total por } \\
\text { busca }\end{array}$ & $\begin{array}{c}\text { Total sem } \\
\text { duplicidades }\end{array}$ & Percentual \\
\hline Transport & Land use & Accessibility & Individual/People & & 6 & \multirow{5}{*}{86} & \multirow{5}{*}{$7,43 \%$} \\
\hline Land use & Accessibility & Individual/People & Mobility & & 6 & & \\
\hline Accessibility & Individual/People & Mobility & Transport & & 70 & & \\
\hline Individual/People & Mobility & Transport & Land use & & 7 & & \\
\hline Mobility & Transport & Land use & Accessibility & & 18 & & \\
\hline \multicolumn{5}{|c|}{ Combinações com cinco palavras + social exclusion } & $\begin{array}{l}\text { Total por } \\
\text { busca }\end{array}$ & $\begin{array}{c}\text { Total sem } \\
\text { duplicidades }\end{array}$ & Percentual \\
\hline Transport & Land use & Accessibility & Individual/People & Mobility & 3 & 3 & $0,25 \%$ \\
\hline \multirow{2}{*}{\multicolumn{6}{|c|}{ Combinações com uma, duas, três, quatro e cinco palavras + social exclusion }} & & \\
\hline & & & & & & 1.157 & $100 \%$ \\
\hline
\end{tabular}

Fonte: própria

O total de artigos encontrados foi 1.157 , sendo que 860 deles foram resultantes de pesquisas considerando duas palavras-chave, 208 resultaram de buscas com três palavras-chave e 86 foram obtidos através de buscas considerando quatro palavraschave. Pesquisas que incluíram as cinco palavras resultaram em apenas 3 artigos. Portanto, na medida em que são acrescentadas mais palavras-chave, ou seja, mais elementos do SMU, o número de trabalhos encontrados reduz. Nas combinações que incluem as palavras-chave duas a duas, observa-se uma tendência quanto ao protagonismo dos Transportes, sendo que nas 4 combinações com os maiores quantitativos de trabalhos encontrados, 3 delas envolvem os Transportes (Transport + Mobility = 369; Transport + Individual/People = 322; Transport + Accessibility $=320$ ). Também se destaca o peso da Mobilidade envolvendo os 2 maiores quantitativos: com o Individual/People, que resultou em 411 trabalhos e com Transport, com os 369 trabalhos já citados. 
Nas combinações entre três palavras-chave, observa-se uma redução expressiva de trabalhos: apenas 208 , o que equivale a $17,97 \%$ de todos os trabalhos encontrados nas buscas. Nas três combinações de palavras que resultaram em maiores quantitativos de trabalhos encontrados, a Acessibilidade se destaca (Transport + Accessibility + Mobility = 190; Transport + Accessibility + Individual/People $=173 ;$ Accessibility + Individual/People + Mobility = 154). Observa-se, ainda, que os menores quantitativos de trabalhos foram resultantes de buscas incluindo-se a palavra-chave "Land use", o que também ocorreu nas buscas considerando duas palavras-chave.

A redução no número de trabalhos encontrados é ainda mais expressiva nas combinações com quatro palavras-chave: 86 , que corresponde a apenas $7,43 \%$ de todos os trabalhos encontrados. Destaca-se o peso significativo da combinação com as palavras "Transport" + "Accessibility" + "Individual/People" + "Mobility" (70 trabalhos), que representa mais de $73,68 \%$ dos trabalhos encontrados e não inclui a palavra "Land use". Dentre as combinações que incluem a palavra "Land use", o resultado com maior quantitativo de trabalhos é o que também inclui as palavras "Transport", "Accessibility" e "Mobility" (18 trabalhos, o que equivale a $20,93 \%$ dos trabalhos encontrados).

A busca realizada a partir da combinação das cinco palavras-chave resultou em 3 trabalhos (SMITH; RICHARDS, 2013; JÄRV et al., 2018; POT et al., 2020), o que representa apenas $0,25 \%$ do total encontrado em toda a pesquisa bibliométrica. Observase que os três trabalhos se destacam por abordarem conjuntamente os Transportes, Uso do Solo, Acessibilidade, Indivíduo e Mobilidade, de forma abrangente e orientada à inclusão social.

No trabalho de Smith e Richards (2013), há uma ênfase ao setor do turismo e suas atividades. Järv et al. (2018) desenvolveram uma estrutura conceitual de modelagem da acessibilidade baseada na localização dinâmica (considerando também as características do uso do solo e dos transportes), o que se refere à temporalidade dinâmica das pessoas, bem como dos transportes e dos locais de atividades. Os autores consideram o conhecimento acerca das disparidades espaço-temporais como algo de fundamental relevância na pesquisa relacionada à equidade social. No trabalho de Pot et al. (2020), a amplitude dos fatores que envolvem a pobreza de transporte e a interação complexa com elementos qualitativos, realçaram e valorizaram o papel da percepção dos indivíduos e suas experiências nos estudos de acessibilidade e exclusão social. Assim, apesar das contribuições relevantes destes três trabalhos, eles compreendem aspectos mais 
específicos, diferentemente da proposta deste artigo baseada no Sistema de Mobilidade Urbana.

Em síntese, a pesquisa bibliométrica desenvolvida neste artigo é convergente ao panorama apresentado na Seção 2, referente aos trabalhos sobre exclusão social, na medida em que sugere algumas tendências relacionadas aos transportes, uso do solo, acessibilidade, indivíduo e mobilidade. Ressalta-se que esses 5 elementos se destacaram e compõem o SMU, conforme indica a revisão de literatura. Tal tendência foi esquematizada qualitativamente na Figura 2. Verifica-se que o número de trabalhos disponíveis na literatura diminui com o aumento de elementos contemplados. Além disso, são observadas diferenças nas interações entre tais elementos, sendo que as relações que apresentaram maior intensidade estão atreladas aos transportes e as que apresentam menor intensidade envolvem o uso do solo, talvez por este já estar implicitamente considerado na acessibilidade.

A partir da identificação dos principais elementos que costumam ser usados nos estudos sobre exclusão social relacionada ao acesso às localidades para realização de atividades, realizada na Seção 2, a pesquisa bibliométrica mostra que o enfoque observado na literatura ainda é predominantemente isolado, com ênfase sobre os transportes. A revisão de literatura e a revisão bibliométrica realçam a necessidade de ampliação do enfoque, incluindo todos os elementos que se destacaram e fazem parte do SMU. Além disso, os resultados desta Seção 3 mostram que somente três trabalhos $(0,25 \%$ de toda a amostra pesquisada) incorporam em sua totalidade os principais elementos do SMU, o que sugere que o atributo da abrangência não recebe a devida atenção na literatura consultada. Nestes três trabalhos, que se preocuparam com esse atributo - condição necessária, mas não suficiente para uma visão de conjunto e integrada - não se observou tal enfoque. Com isso, este trabalho identifica como uma lacuna da literatura a necessidade da abrangência e da abordagem sistêmica, que deve considerar a natural interação entre todos os cinco elementos, bem como deles com a exclusão social. Sendo assim, este trabalho busca, em sua Seção 4, contribuir para o preenchimento de tal lacuna. 


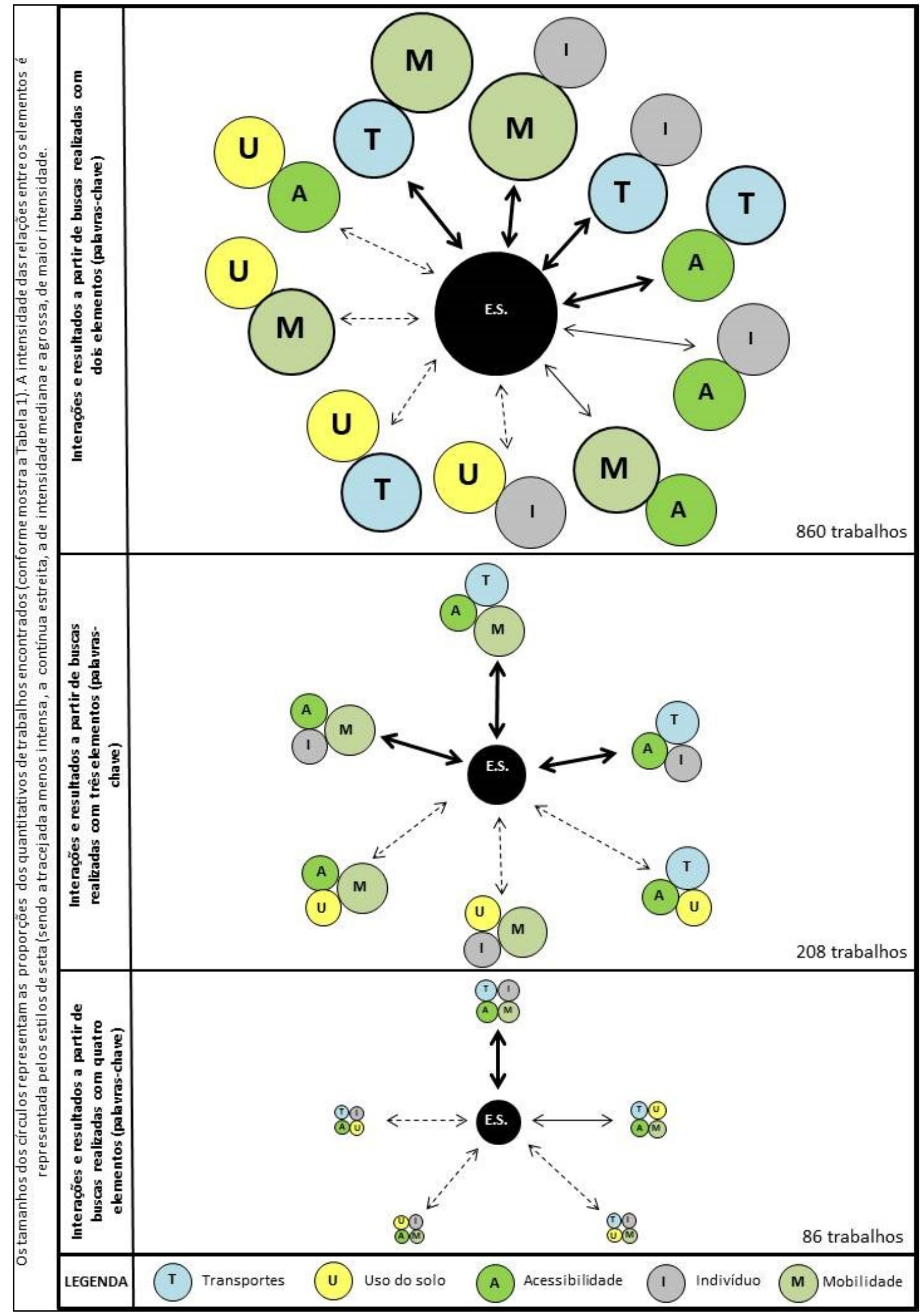

Figura 2 - Panorama geral da quantidade dos trabalhos sobre exclusão social relacionada aos elementos do SMU conforme a pesquisa bibliométrica.

Fonte: própria. 


\section{FUNDAMENTOS PARA UM SMU ORIENTADO À INCLUSÃO SOCIAL}

Os resultados apresentados nas seções anteriores confirmaram o que vem sendo defendido por vários autores (LUCAS, 2004; CASS et al., 2005; CURRIE 2011; SILVA, 2013; MATTIOLI; COLLEONI, 2016; KAMRUZZMAN et al., 2016) quanto à necessidade de abordagens abrangentes e integradas, com foco na inclusão social e a partir de princípios sistêmicos; o que não tem sido observado na literatura consultada (MACÊDO et al., 2008; MEADOWS, 2009; NACIFF; KNEIB, 2020). O desafio desta seção é sugerir alguns fundamentos que podem nortear e contribuir para a concepção de um SMU orientado à inclusão social.

Neste trabalho, assume-se que um sistema pode ser caracterizado como um conjunto de subsistemas e componentes que se relacionam e se organizam, a fim de alcançar um dado objetivo. Em função de sua complexidade e relações com múltiplos fatores, o SMU apresenta características próprias de todo sistema, como a consistência baseada em um "todo" composto por diferentes elementos que possuem um objetivo em comum e que estabelecem entre si relações de interconexão e também interagem com o ambiente externo (MACÊDO et al., 2008; MEADOWS, 2009; NACIFF e KNEIB, 2020). Para apresentar o SMU a partir do conceito de sistema, cabe destacar alguns aspectos quanto aos fundamentos propostos, envolvendo: o objetivo do SMU; seus subsistemas e respectivos significados e propósitos; as relações e articulações entre os subsistemas em prol do cumprimento de suas funções com foco na inclusão social.

Diante dos problemas decorrentes de deficiências no planejamento e de desigualdades, bem como da importância em garantir aos indivíduos o acesso às atividades, o objetivo do SMU a ser realçado neste artigo é o de contribuir para a inclusão social. Entretanto, reconhece-se ser esta apenas uma das faces da Mobilidade Urbana Sustentável, que acrescenta ao planejamento o viés social. Além da mobilidade inclusiva, a abrangência do conceito de sustentabilidade sugere agregar e valorizar outras dimensões, na busca por uma mobilidade segura, justa socialmente, produtiva, verde e com qualidade (PORTUGAL, 2017). Para alcançar tais atributos, é fundamental que o planejamento e gestão dos transportes, do uso do solo, da acessibilidade e da mobilidade estejam voltados para a sustentabilidade através da redução da demanda do tráfego motorizado e incentivo às escolhas mais sustentáveis na programação das viagens.

O desafio de que o SMU seja comprometido com a inclusão social (LUCAS, 2004, CASS et al., 2005; CURRIE 2011; SILVA, 2013; MATTIOLI; COLLEONI, 2016; KAMRUZZMAN et al., 2016), requer uma abordagem que envolva os cinco elementos 
identificados na revisão: transportes, uso do solo, acessibilidade, indivíduo e mobilidade. Considerando-se o conceito de sistema, tais elementos podem ser entendidos como subsistemas, que interagem entre si e com a exclusão social, de maneira a alcançar o objetivo do SMU. A fim de melhor compreender estas relações e o modo como devem ser organizadas, é importante conhecer os significados e propósitos de cada um dos seus subsistemas, conforme apresentado no Quadro 1.

Quadro 1 - Conceitos e propósitos dos subsistemas do SMU.

\begin{tabular}{|c|c|c|}
\hline & SIGNIFICADO & PROPÓSITO \\
\hline 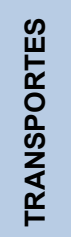 & $\begin{array}{l}\text { Compreende as infraestruturas e serviços destinados à } \\
\text { realização das viagens e deslocamentos de pessoas que } \\
\text { pretendem alcançar as atividades distribuídas no espaço } \\
\text { urbano. }\end{array}$ & $\begin{array}{l}\text { Proporcionar acesso das pessoas às atividades, com } \\
\text { qualidade e com atributos que promovam a mobilidade e o } \\
\text { desenvolvimento inclusivos. }\end{array}$ \\
\hline $\begin{array}{l}\text { 응 } \\
\text { 옹 }\end{array}$ & $\begin{array}{l}\text { Representa as características do desenvolvimento e do espaço } \\
\text { urbano. Inclui as atividades, bem como a forma como elas se } \\
\text { distribuem espacialmente nas diferentes escalas urbanas } \\
\text { (macro, meso e micro). Exerce influência sobre as condições de } \\
\text { acesso e sobre a natureza dos fluxos das viagens no território. }\end{array}$ & $\begin{array}{l}\text { Organizar e qualificar o espaço urbano, nas escalas } \\
\text { macro, meso e micro, em sintonia com o desenvolvimento } \\
\text { e mobilidade inclusivos, proporcionando às pessoas a } \\
\text { proximidade e acesso às atividades por modos não } \\
\text { motorizados. O uso do solo também deve buscar uma } \\
\text { distribuição mais equilibrada dos fluxos das viagens } \\
\text { motorizadas, que cobrem distâncias maiores. }\end{array}$ \\
\hline 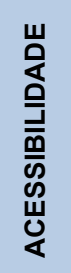 & $\begin{array}{l}\text { Condição de alcance das atividades determinada por } \\
\text { características locacionais e individuais. Depende dos } \\
\text { transportes e do uso do solo, mas fundamentalmente da } \\
\text { integração entre eles. A acessibilidade determina a impedância } \\
\text { ou função desutilidade associada ao ato de se deslocar, nas } \\
\text { escalas macro, meso e micro. }\end{array}$ & $\begin{array}{l}\text { Conceber condições de acesso às atividades que } \\
\text { promovam a mobilidade e o desenvolvimento inclusivos, a } \\
\text { partir da articulação entre transportes e uso do solo e } \\
\text { considerando a capacidade, características e e } \\
\text { necessidades dos indivíduos. }\end{array}$ \\
\hline$\stackrel{\circ}{\stackrel{0}{2}}$ & $\begin{array}{l}\text { Considera as características sociais, econômicas e psicológicas } \\
\text { de indivíduos, grupos ou comunidades, que podem determinar a } \\
\text { percepção e a capacidade de superação da impedância } \\
\text { associada à acessibilidade. A partir de tais características, cada } \\
\text { indivíduo decide sobre a realização (ou não) do deslocamento e } \\
\text { sua programação (que envolve a escolha do local, modalidade, } \\
\text { horário, etc. que constituem os padrões de viagem) das } \\
\text { atividades que pretende alcançar. }\end{array}$ & $\begin{array}{l}\text { Dispor de condições e capacidade que permitam ao } \\
\text { indivíduo acessar e participar das atividades desejadas e } \\
\text { de forma inclusiva. }\end{array}$ \\
\hline 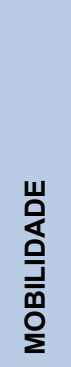 & $\begin{array}{l}\text { Movimentação de pessoas que necessitam ou desejam alcançar } \\
\text { atividades fisicamente e se expressa pelos padrões de viagens, } \\
\text { incluindo as não realizadas (interpretadas como uma exclusão } \\
\text { ou como opção à acessibilidade digital por meio dos serviços de } \\
\text { telecomunicações). Tais padrões resultam da interação entre as } \\
\text { características e habilidades dos indivíduos e a impedância } \\
\text { derivada da acessibilidade (transportes e uso do solo) a ser } \\
\text { superada, o que envolve os quatro subsistemas citados } \\
\text { anteriormente. }\end{array}$ & $\begin{array}{l}\text { Expressar padrões de viagens inclusivos, comprometidos } \\
\text { com a mobilidade e o desenvolvimento inclusivos, levando } \\
\text { em conta não só a quantidade dos deslocamentos, mas } \\
\text { também a qualidade com que eles são realizados quanto } \\
\text { às internalidades (usuários) e às externalidades } \\
\text { (sociedade), além do déficit de viagens (imobilidade). }\end{array}$ \\
\hline
\end{tabular}

Fonte: SCHÖNFELDER; AXHAUSEN (2003); STANLEY et al. (2011); GUTIERREZ (2012); MELLO (2015); ASTON et al. (2016); KAMRUZZAMAN et al. (2016); MARTENS (2016); FALAVIGNA et al. (2017); KNEIB; PORTUGAL (2017); PORTUGAL; SILVA (2017); LIMA; PORTUGAL (2021); LITMAN, (2020). 
Cada um dos subsistemas do SMU tem propósitos distintos, que se articulam e se complementam para desempenhar suas respectivas funções. Conforme apresenta o Quadro 1, os significados e propósitos dos subsistemas Transportes, Uso do Solo e Acessibilidade têm em comum e convergem para a função de promover condições de acesso inclusivo dos indivíduos às atividades, que proporcionem uma mobilidade e desenvolvimento inclusivos. O Uso do Solo, que expressa a forma como as atividades estão distribuídas no território, tem um compromisso social e representa um recurso coletivo (MARTENS, 2016; LITMAN, 2020). O mesmo ocorre com os Transportes, que também podem ser entendidos como um tipo de uso do solo, já que envolvem as infraestruturas e serviços disponibilizados à população para que esta realize deslocamentos e acessem as atividades (PORTUGAL, 2017). Outro recurso coletivo é a Acessibilidade, tendo em vista que ela é o resultado da interação entre Transportes e Uso do Solo (ASTON et al., 2016). Tais recursos coletivos são escassos e, consequentemente, alvos de políticas do SMU destinadas a priorizar sua utilização em conformidade com o interesse público, como o de promover condições de acesso inclusivo às atividades, que é a função atribuída a eles.

Os indivíduos configuram o quarto subsistema, cuja função é promover a capacidade destes de superar impedâncias de acesso fornecidas pelos três subsistemas citados anteriormente. De distintas naturezas - social, econômica, física, psicológica - os recursos individuais podem ser barreiras para o usufruto dos recursos coletivos. É fundamental que os planejadores do SMU conheçam tais recursos individuais e os considerem a fim de proporcionar oferta justa e equitativa dos recursos coletivos. Com isso, espera-se que os indivíduos tenham a capacidade de realizar seus deslocamentos de forma adequada, o que reflete na mobilidade inclusiva. Ao interagir com as condições de acesso, cabe ao indivíduo decidir se a atividade pretendida por ele será realizada presencialmente ou de forma virtual, ou seja, sem a necessidade de se deslocar fisicamente. Quando o indivíduo opta por realizar tal deslocamento, também cabe a ele decidir de que forma ocorrerá e com quais escolhas na programação das viagens. Em todos os casos, o subsistema de mobilidade resulta desta interação entre os recursos coletivos (condições de acesso) e recursos individuais (capacidade de superar impedâncias de acesso), sendo a sua função promover a mobilidade inclusiva.

A articulação entre os subsistemas refletirá o nível de atendimento das três funções do SMU: 1. Promover o acesso inclusivo; 2. Promover a capacidade dos indivíduos de superar impedâncias; 3 . Promover a mobilidade inclusiva. O potencial de inclusão social 
promovido pelo SMU pode ser identificado através de análises das articulações entre os subsistemas Transportes, Uso do Solo e Acessibilidade com o acesso e destes com os indivíduos na promoção da mobilidade. Pressupõe-se que isso se dá na medida em que são promovidos em diferentes níveis o acesso inclusivo e a capacidade dos indivíduos em superar impedâncias de acesso que são, respectivamente, as funções dos recursos coletivos e individuais na busca pela mobilidade inclusiva. A Figura 3 esquematiza as relações entre os subsistemas e suas funções, que têm em comum o objetivo de contribuir para a inclusão social.

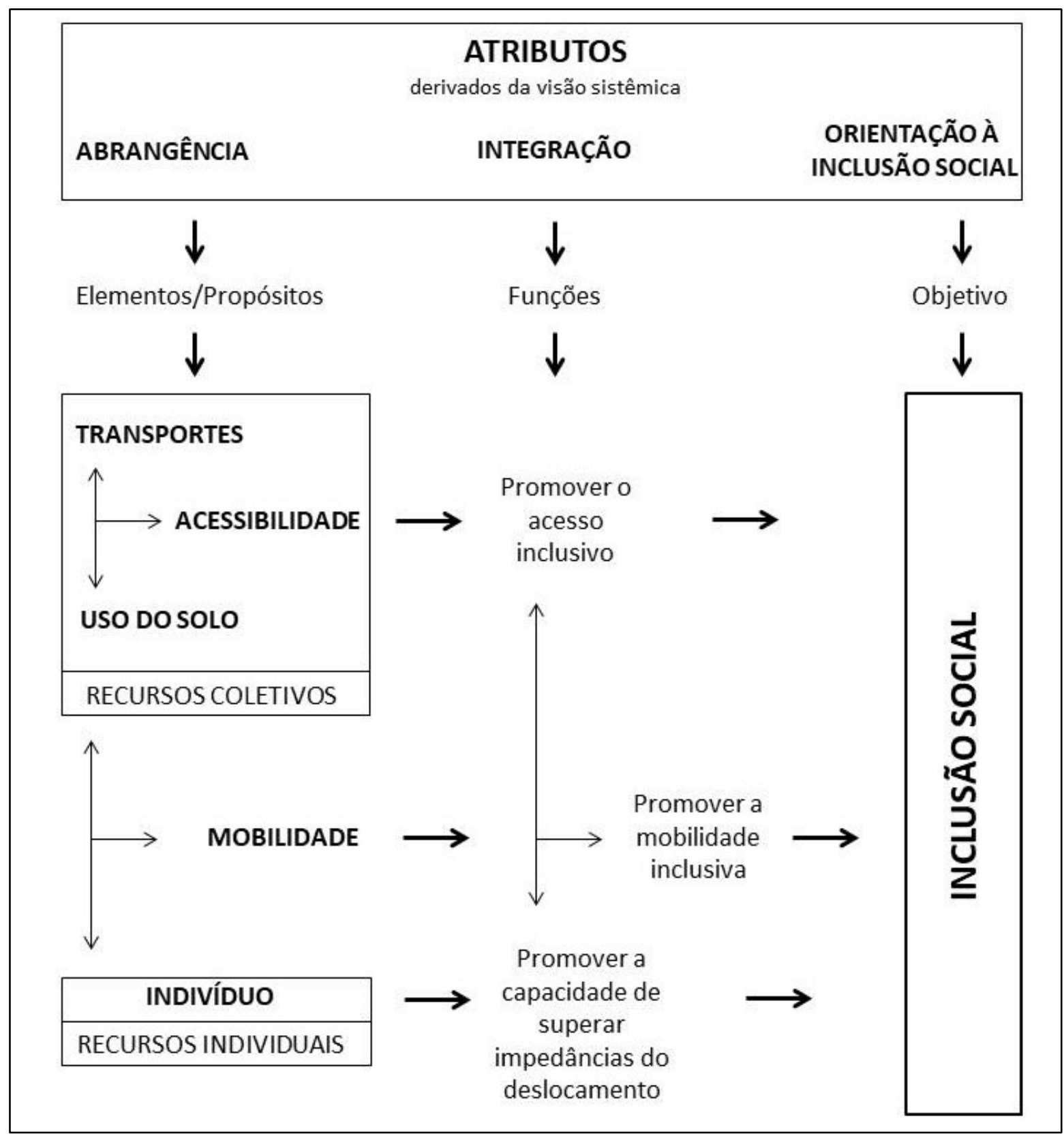

Figura 3 - Esquema dos subsistemas do SMU e suas funções para promover a inclusão social. Fonte: própria. 
A estrutura proposta expressa a complexidade que envolve as relações entre o SMU e a inclusão social, o que permite entender as limitações entre as funções e de suas relações com a inclusão social. Ainda que as políticas destinadas ao SMU busquem promover a inclusão social a partir dos recursos coletivos, isso não garante que tal objetivo seja cumprido. Há a interferência de outros fatores sobre a inclusão social, dentre os quais as características, necessidades e capacidade dos indivíduos em superar as impedâncias associadas à acessibilidade, o que depende não só dos recursos financeiros, mas também físicos e emocionais. Padrões de viagens que indiquem alta taxa de imobilidade nem sempre refletem que o subsistema Mobilidade não se mostre inclusivo, pois os indivíduos podem realizar suas atividades também de forma virtual.

Devido à complexidade dos conceitos de exclusão social, do SMU e das relações entre eles e com o ambiente urbano, naturais limitações são observadas. Indicadores de privação, dentre os quais a renda, baixa escolaridade e pouco poder político, são apenas causas ou fatores de risco da exclusão social. No entanto, a exclusão social não se aplicaria se, mesmo com todas as condições adversas, os indivíduos fossem capazes de participar das diferentes dimensões de atividades, dentre as quais o consumo, produção, saúde, educação, participação política e interação social (BURCHARDT et al., 2002; STANLEY et al., 2011). Além disso, mesmo que ocorra o acesso ao local onde a atividade se realiza, isto não garante a participação do indivíduo nela. Estes contextos apontam para uma limitação: a exclusão social envolve aspectos que estão além do escopo de atuação do SMU e dependem de políticas em outros setores, como saúde, cultura, lazer e educação (LIMA; PORTUGAL, 2021). Dessa forma, o SMU não pode, de forma isolada, resolver os problemas da exclusão social, mas sim contribuir para a redução do potencial de exclusão e contribuir para a promoção da inclusão social.

A importância da abordagem sistêmica é explicitada na Figura 3. Este atributo permite uma melhor compreensão acerca do papel de cada subsistema e das interações entre eles e deles com a inclusão social. Além disso, a abordagem sistêmica revela as limitações de um enfoque isolado e fragmentado em detrimento de uma visão de conjunto e integrada para interpretar os potenciais impactos do SMU na inclusão social. Além disso, as limitações e relações entre os três subsistemas para alcançar seus propósitos sugerem um olhar articulado, a fim de cumprir com a sua função de conceber condições de acesso inclusivo.

Além das interações entre seus subsistemas, o SMU também interage com elementos externos a ele e que convergem para os diversos setores da sociedade, entre 
os quais há interesses em comum, mas também interesses conflitantes. Essa dinâmica realça a importância do planejamento urbano pautado na justiça social e na democracia, já que a inclusão social requer a justa distribuição de benefícios e custos. Os Planos de Mobilidade Urbana Sustentável (PMUS) devem estar voltados para a defesa das necessidades coletivas das cidades e das pessoas, de maneira a garantir o bem comum a todos e, assim, fortalecer a interação entre todos os atores através do diálogo e do reconhecimento dos direitos, necessidades e potenciais contribuições de cada um dos segmentos da sociedade (MARGUTI et al., 2016). Os objetivos do SMU envolvem a promoção de condições de deslocamento com qualidade, para todos os indivíduos, de maneira que tais deslocamentos atendam às necessidades de toda a população e despendam a ela custos aceitáveis e compatíveis com suas condições (tempo, distância, financeiro, etc.). $\mathrm{O}$ alcance de tais objetivos envolve significativa complexidade, o que aponta para a necessidade de instrumentos de apoio ao planejador no gerenciamento do SMU. Estudos como o apresentado neste trabalho podem fornecer uma contribuição para elaborar e aplicar tais instrumentos.

Sendo assim, cabe destacar a necessidade de se avançar no desenvolvimento de uma concepção que insira tais elementos e fundamentos em processos de elaboração e gestão de PMUS. Dessa forma, tal concepção possibilita analisar, em uma cidade ou metrópole, as atuais condições do SMU e seu potencial de impacto na inclusão social, identificando os subsistemas e componentes que se mostrarem mais críticos. A falta de conexão entre as medidas recomendadas pelas abordagens tradicionais de planejamento e as efetivas necessidades de mobilidade acentua os problemas de exclusão já vivenciados em contextos desiguais e com déficit de dados e de planejamento urbano integrado. Portanto, é fundamental uma abordagem sistêmica, que forneça uma visão estratégica, derivada de um ambiente participativo e transparente, que seja usada no desenvolvimento de PMUS.

\section{TÓPICOS CONCLUSIVOS}

Diante das lacunas observadas nos estudos sobre exclusão social relacionada ao acesso às atividades, este trabalho se desenvolveu com o objetivo de contribuir para uma melhor compreensão acerca das relações entre o SMU e a exclusão social. Para atender a tal objetivo, uma proposta foi apresentada a partir de uma visão integrada e estratégica, potencialmente indicada para elaboração dos Planos de Mobilidade Urbana Sustentável, especialmente em contextos urbanos desiguais e com deficiências no planejamento. 
Tal contribuição pode ser útil na formulação de políticas e medidas mais compatíveis com as reais necessidades dos indivíduos. Para isto, é importante avançar nessa concepção e inseri-la em um processo de análise e decisão. Cabe ressaltar, no entanto, que o SMU orientado à inclusão social não garante que a sociedade usufrua de uma ampla inclusão. Por outro lado, a falta de um SMU orientado à inclusão social aumenta o potencial de exclusão social.

O planejamento e gestão do SMU requerem o conhecimento e a consideração de especificidades que refletem a complexidade da exclusão social e do próprio SMU, conforme abordado neste trabalho. Nesse sentido, a seguir são destacadas tais especificidades, que indicam itens identificados, mas ainda não trabalhados, ou limitações que podem ser encontradas no âmbito da proposta apresentada, constituindo desafios para serem investigados e considerados em propostas futuras, segundo os seguintes aspectos:

Quanto à delimitação do SMU:

- Apesar da ênfase ao acesso físico às atividades, é importante considerar também o acesso virtual, sendo que as taxas de imobilidade devem ser cuidadosamente analisadas, a fim de que sejam corretamente interpretadas para avaliar se a mobilidade é ou não inclusiva. Nesses casos, costuma-se incluir as características socioeconômicas, com vistas a identificar indivíduos que tendem a dispor ou não do acesso virtual, aplicando os devidos ajustes.

- No âmbito financeiro, transcende a competência de atuação e intervenção de políticas do SMU o aumento de recursos individuais destinados a ampliar a capacidade dos indivíduos mais vulneráveis ao acesso aos transportes e às atividades. Por outro lado, no âmbito dos recursos coletivos, o SMU pode conceber condições de acessibilidade que favoreçam modalidades mais inclusivas, como os transportes ativo e público, de acordo com as limitações dos grupos mais vulneráveis quanto às carências de acesso e mobilidade. Dessa forma, as políticas do SMU implicam na sintonia e sensibilidade das condições de acesso com relação aos grupos em desvantagem.

Quanto à delimitação da mobilidade inclusiva em relação à sustentável:

- A mobilidade inclusiva é apenas uma das faces da mobilidade sustentável, o que se reflete no uso de padrões de viagens mais específicos, o que pode resultar em uma mobilidade inclusiva, mas não sustentável. Nesses casos, padrões de viagens que 
atendam aos quesitos exigidos pela inclusão social podem não contemplar escolhas mais sustentáveis na programação dos deslocamentos, por exemplo, a escolha modal centrada nos automóveis.

Quanto à representação e mensuração das três funções (e respectivos subsistemas):

- Devido à amplitude e complexidade do conceito de acessibilidade, há dificuldades práticas de utilização de indicadores para mensurar a função do acesso inclusivo.

- Renda e recursos financeiros se destacam como principais indicadores da capacidade de superar impedâncias, o que pode minimizar outras dimensões que também afetam tanto a percepção quanto a própria capacidade de superar as impedâncias associadas à acessibilidade, dentre as quais a física e a emocional.

- A representação da mobilidade inclusiva é feita essencialmente por padrões de viagens que poderiam explicar a não realização dos deslocamentos físicos (como a taxa de imobilidade), ou o esforço para fazê-lo (como o tempo ou o custo de viagem efetivamente gasto pelos usuários). Contudo, não compreendem outros fatores que podem determinar a decisão de realizar ou não a viagem e sua respectiva programação.

- Existem dificuldades no acesso a dados, em quantidade e qualidade suficientes para o planejamento urbano e da mobilidade, que permitam fornecer uma base de conhecimentos e informações para se modelar e mensurar indicadores, funções e subsistemas.

Quanto à interação do SMU com o ambiente urbano:

- Por se inter-relacionarem, o SMU e o ambiente urbano, especificidades de cada localidade tais como marcos institucionais, características socioeconômicas, ambientais, culturais, comportamentais da população e seus distintos grupos, podem interferir nas escolhas e decisões de viagem de toda a sociedade. Nesses casos, destacam-se a desigualdade, violência e competência da administração em cumprir com suas atribuições, como as associadas ao SMU.

Quanto à complexidade da exclusão social e sua relação com o SMU:

- Na medida em que o propósito do SMU orientado à inclusão se limita ao alcance da atividade, vários outros fatores também podem impactar na realização de tal atividade, consequentemente, na inclusão ou exclusão social. 
Dentre as sugestões de trabalhos futuros, apresenta-se a revisão sistemática, que será fundamental para confirmar com mais precisão os quantitativos identificados na pesquisa bibliométrica desenvolvida neste trabalho. Outra sugestão de trabalho futuro é o aprofundamento da abordagem desenvolvida neste artigo, na qual os elementos e fundamentos que fazem parte do SMU, identificados neste trabalho, podem ser desenvolvidos e darem início à concepção de um Sistema de Mobilidade Urbana Inclusivo (SMUI). Nesse sentido, a identificação de condições e obstáculos para o cumprimento das funções do SMUI pode auxiliar o aprofundamento desta concepção, assistindo a gestão pública na tomada de decisão, ou, ainda, favorecendo que uma visão estratégica e sistêmica seja adotada nos PMUS, contribuindo para reduzir o potencial de exclusão social.

\section{AGRADECIMENTOS}

Agradecemos ao CNPq pelo apoio às nossas bolsas de pesquisa.

\section{REFERÊNCIAS}

ASTON, L. C.; CURRIE, G.; PAYKOVA, K. Does transit mode influence the transit-orientation of urban development? An empirical study. Journal of Transport Geography, v. 55, P. 8391, 2016.

ATKINSON, A. B.; HILLS, J. Exclusion, Employment and Opportunity. 1. ed. London: Centre for Analysis of Social Exclusion, 1999. 128p.

BARATA, R. B. Como e por que as desigualdades sociais fazem mal à saúde. Rio de Janeiro: Editora FioCruz, 2009. 120p.

BERTALANFFY, L. V. Teoria geral dos sistemas: fundamentos, desenvolvimento e aplicações. Petrópolis: Vozes, 2010. 360p.

BOCAREJO, J. P.; OVIEDO, D. R. Transport accessibility and social inequities: a tool for identification of mobility needs and evaluation of transport investments. Journal of Transport Geography, v. 24, p. 142-154, 2012.

BURCHARDT, T. Le Grand, J. E Piachaud, D. Introduction. In: Hills, J., Le Grand, J. and Piachaud, D. (Orgs.) Understanding social exclusion. Oxford: Oxford University Press, 2002.

CARNEIRO, M.; TOLEDO, J.; AURÉLIO, M.; ORRICO, R. Espraiamento urbano e exclusão social. Uma análise da acessibilidade dos moradores da cidade do Rio de Janeiro ao mercado de trabalho. Eure, v. 45, n. 136, p. 51-70, 2019.

CARRUTHERS, R.; DICK, M.; SAURKAR, A. Affordability of public transport in developing countries. Washington: World Bank, 2005. 27 p. 
CASAS, I.; DELMELLE, E. C. Identifying dimensions of exclusion from a BRT system in a developing country: a content analysis approach. Journal of Transport Geography, v. 39, p. 228-237, 2014.

CASS, N.; SHOVE, E.; URRY, J. Social exclusion, mobility and access. The sociological Review, v. 53, n. 3, p. 539-555, 2005.

CHENG, J.; BERTOLINI, I.; LE CLERCQ, F. Measuring sustainable accessibility. Transportation Research Record: Journal of the Transportation Research Board, v. 1, p. 1625, 2007.

CHURCH, A.; FROST, M.; SULLIVAN, K. Transport and social exclusion in London. Transport Policy, v. 7, p. 195-205, 2000.

CURRIE, G. (Ed.) New perspectives and methods in transport and social exclusion research. Emerald: Bingley, 2011. 310p.

EWING, R.; CERVERO, R. Travel and built environment: a synthesis. Transportation Research Record, v. 1780, n. 01, p. 87-114, 2001.

FALAVIGNA, C.; RODRIGUES, T. G.; HERNÁNDEZ, D. Mobilidade inclusiva. In: PORTUGAL, L. S. (Org.). Transporte, mobilidade e desenvolvimento urbano. Rio de Janeiro: Elsevier, 2017. p. 219-238.

GAO, K.; SUN, L.; YANG, Y.; MENG, F.; QU, X. Cumulative prospect theory coupled with multi-attribute decision making for modeling travel behavior. Transportation Research, $v$. 148 , p. 1-21, 2021.

GARCIA, C. S. H. F.; MACÁRIO, M. R. M. R.; MENEZES, E. D. A. G.; LOUREIRO, C. F. G. Strategic Assessment of Lisbon's Accessibility and Mobility Problems from an Equity Perspective. Networks \& Spatial Economics, v. 18, p. 1-25, 2018.

GIUFFRIDA, N.; IGNACCOLO, M.; INTURRI, G.; ROFÈ, Y.; CALABRÒ, G. Investigating the correlation between transportation social need and accessibility: the case of Catania. Transportation Research Procedia, v. 27, p. 816-823, 2017.

GRAY, D.; SHAW, J.; FARRINGTON, J. Community transport, social capital and social exclusion in rural areas. Area, v. 38, p. 89-98, 2006.

GUTIÉRREZ, A. ¿Qué es la movilidad? Elementos para (re)construir las definiciones básicas del campo del transporte. Bitácora 21, v. 74, p. 61-74, 2012.

GUTIÉRREZ-SALCEDO, M.; MARTÍNEZ, M. A.; MORAL-MUNOZ, J.; HERRERA-VIEDMA, E.; TORRES-ALBERO, C.; COBO, M. J. Some bibliometric procedures for analysing and evaluating research fields. Applied Intelligence, v. 48, p. 1275-1287, 2018.

HERCE, M. Sobre la movilidad en la ciudad: propuestas para recuperar un derecho ciudadano. Barcelona: Reverté, 2009. 328p.

JARY, O.; TENKANEN, H.; SALONEM, M.; AHAS, R.; TOIVONEN, T. Dynamic cities: location-based accessibility modeling as a function of time. Applied Geography, v. 95, p. 101110, 2018. 
JONES, P. The evolution of urban mobility: the interplay of academic and policy perspectives. IATSS Research, v. 79, p. 7-13, 2014.

KNEIB, E. C.; MELLO, A. J. R.; GONZAGA, A. S. Macroacessibilidade orientada à equidade e à integração do território. In: PORTUGAL, L. S. (Org.). Transporte, mobilidade e desenvolvimento urbano. Rio de Janeiro: Elsevier, 2017. p. 119-134.

KNEIB, E. C.; PORTUGAL, L. S. Caracterização da acessibilidade e suas relações com a mobilidade e o desenvolvimento. In: PPORTUGAL, L. S. (Org.). Transporte, mobilidade e desenvolvimento urbano. Rio de Janeiro: Elsevier, 2017. p. 65-87.

KAMRUZZAMAN, M. D.; YIGITCANLAR, T.; YANG, J.; MOHAMED, M. A. Measures of transport-related social exclusion: a critical review of the literature. Sustainability, v. 8, p. 696, 2016.

KENYON, S.; LYOND, G.; RAFFERTY, J. Transport and social exclusion: investigating the possibility of promoting inclusion through virtual mobility. Journal of Transport Geography, v. 10, n. 3, p. 207-219, 2002.

KENYON, S. Understanding social exclusion and social inclusion. Municipal Engineer, v. 156, p. $97-104,2003$.

KWAN, M.; WEBER, J. Individual accessibility revisited: implications for geographical analysis in the twenty-first century. Geographical Analysis, v. 34, n. 4, p. 341-353, 2003.

LIMA, G. C. L. S.; PORTUGAL, L. S. Understanding transport related social exclusion through the lens of capabilities approach. Transport Reviews, 2021.

LITMAN, T. Evaluating Accessibility for Transport Planning - measuring people's ability to reach desired goods and activities. Victoria: Victoria Transport Policy Institute, 2020. $64 \mathrm{p}$.

LUCAS, K. (Ed.) Running on empty. Transport, social exclusion and environmental justice. Briston: The Policy Press, 2004. 320p.

LUCAS, K. Transport and social exclusion: where are we now? Transport Studies Unit, University of Oxford, Transport Policy, v. 20, p. 105-113, 2012.

LYONS, G. The role of information in decision making for transport. Technical Report. BIS: Department for Business Innovation and Skills, 2006. 20p.

MACÊDO, M. H.; SILVA, A. N. R.; COSTA, M. S. Abordagem sistêmica da mobilidade urbana: reflexões sobre o conceito e suas implicações. In: CONGRESSO LUSO BRASILEIRO PARA O PLANEJAMENTO, URBANO, REGIONAL, INTEGRADO E SUSTENTÁVEL. 3., 2008. Anais... São Carlos: STT/CETEPE/EESC/USP, 2008. p. 1-13.

MARGUTI, B. O.; COSTA, M. A.; GALINDO, E. P. A trajetória brasileira em busca do direito à cidade: os quinze anos de Estatuto da Cidade e as novas perspectivas à luz da Nova Agenda Urbana. In: COSTA, M. A. O Estatuto da Cidade e a Habitat III: um balanço de quinze anos da política urbana no Brasil e a nova agenda urbana. Brasília: Ipea, 2016. p. 11-25.

MARTENS, K. Transport Justice: designing fair transportation systems. Londres: Routledge, 2016. 256 -p. 
MATTIOLI, G.; COLLEONI, M. Transport disadvantage, car dependence and urban form. Springer International Publishing Switzerland, 2016.

MEADOWS, D. H. Thinking in systems: a primer. Sustainability Institute. London, 2009.

MELLO, A. J. R. A acessibilidade ao emprego e sua relação com a mobilidade e o desenvolvimento sustentáveis: o caso da Região Metropolitana do Rio de Janeiro. 2015. $235 \mathrm{f}$. Tese (Doutorado em Engenharia de Transportes) - Universidade Federal do Rio de Janeiro, Rio de Janeiro, 2015.

MILLER, H. J. Social exclusion in space and time. Department of Geography, University of Utah, USA, 2006.

NACIFF, Y. D. N.; KNEIB, E. C. Estrutura espacial e mobilidade urbana: estudo sistêmico aplicado à Região Metropolitana de Goiânia. Caderno de Geografia, v. 30, n. 61, p. 286-307, 2020.

NEUTENS, T.; DANIELS, S.; MINNEN, J.; GLORIEUX, I.; DE MAEYER, P.; VAN DE WEGHE, N. Spatial and temporal fluctuations in individual accessibility: a comparative analysis among subgroups of the population. Danish Journal of Geography, v. 114, n. 2, p. 119-131, 2014.

NUTLEY, S. Indicators of transport and accessibility problems in rural Australia. Journal of Transport Geography, v. 11, n. 1, p. 55-71, 2003.

PEDRO, L. M.; SILVA, M. A. V.; PORTUGAL, L. S. Desenvolvimento e mobilidade sustentáveis. In: PORTUGAL, L. S. (Org.). Transporte, mobilidade e desenvolvimento urbano. Rio de Janeiro: Elsevier, 2017. p. 19-38.

PEREIRA, R. H. M.; BRAGA, C. K. V.; SERRA, B. NADALIN, V. G. Desigualdades socioespaciais de acesso a oportunidades nas cidades brasileiras - 2019. Texto para discussão / Instituto de Pesquisa Econômica Aplicada. Brasília. IPEA, 2019.

PITTMAN, N.; DAY, J. E. Locating and quantifying public transport provision with respect to social need in Canberra, Australia. Australian Planner, v. 52, n. 4, p. 326-336, 2015.

PORTUGAL, L. S.; SILVA, M. A. V. (2017). Índices de Desenvolvimento e Mobilidade Sustentáveis. In: PORTUGAL, L. S. (Org.). Transporte, Mobilidade e Desenvolvimento Urbano. Rio de Janeiro: Elsevier. 2017. p. 39-58.

PORTUGAL, L. S.; MELLO, A. J. R. Um panorama inicial sobre transporte, mobilidade, acessibilidade e desenvolvimento urbano. In: PORTUGAL, L. da S. (org.). Transporte, mobilidade e desenvolvimento urbano. Rio de Janeiro: Elsevier, 2017. p. 1-18.

POT, F. J.; KOSTER, S.; TILLEMA, T.; JORRITSMA, P. Linking experienced barriers during daily travel and transport poverty in peripheral rural areas: the case of Zeeland, the Netherlands. European Journal of Transport and Infrastructure Research, v. 20, n. 3, p. 29-46, 2020.

PRITCHARD J. P.; MOURA, F.; SILVA, J. A.; MARTINEZ, L. M. Spatial analysis of transportation-related social exclusion in the Lisbon metropolitan area. Procedia: Social and Behavioral Sciences, v. 111, p. 440-449, 2014. 
PUCCI, P.; VECCHIO, G.; BOCCHIMUZZI, L.; LANZA, G. Inequalities in job-related accessibility: testing and evaluative approach and its policy relevance in Buenos Aires. Applied Geography, v. 107, p. 1-11, 2019.

SAIF, M. A.; ZEFREH, M. M.; TOROK, A. Public transport accessibility: a literature review. Periodica Polytechinca Transportation Engineering, v. 3, p. 1-8, 2018.

SANTOS, J. A. Desigualdade e o conceito de gênero. Virtú, Juiz de Fora, v. 1. p. 1-3, 2006.

Schönfelder, S. Axhausen, K. W. Activity spaces: measures of social exclusion? Transport Policy, v. 10, n. 4, p. 273-286, 2003.

SCHWANEN, T.; LUCAS, K.; AKYELKEN, N.; SOLSONA, D. C.; CARRASCO, J. A.; NEUTENS, T. Rethinking the links between social exclusion and transport disadvantage through the lens of social capital. Transportation Re-search Part A: Policy and Practice, v. 74, p. 123-135, 2015.

SCHWEDES, O.; HOOR, M. Integrated transport planning: from supply-to demand-oriented planning. Considering the benefits. Sustainability, v. 11, n. 21, p. 5900, 2019.

SHERGOLD, I.; PARKHURST, G. Transport-related social exclusion amongst older people in rural Southwest England and Wales. Journal of Rural Studies, v. 28, p. 412-412, 2012.

SILVA, C. Structural accessibility for mobility management. Progress in planning, v. 81, p. 149, 2013.

SMMITH, M.; RICHARDS, G. The Routledge handbook of cultural tourism. 1. ed. Routledge, 2013. 420p.

SOCIAL EXCLUSION UNIT - (SEU). Making the Connections: Transport and Social Exclusion. Social Exclusion Unit, The Stationery Office: London, UK, 2003.

STANLEY, J.; HENSHER, D. A.; STANLEY, J. R.; CURRIE, G. Social exclusion and the value of mobility. Journal of Transport Economics and Policy, v. 45, n. 2, p. 197-222, 2011.

VAN WEE, B.; GEURS, K. Discussing equity and social exclusion in Accessibility evaluations. European Journal of Transport and Infrastructure Research, v. 11, n. 4, p. 350-367, 2011.

WANG, H.; KWAN, M.; HU, M. Social exclusion and accessibility among low- and non-lowincome groups: a case study of Nanjing, China. Cities, v. 101, 2020. 